\title{
BURIAL HABITS OF HUMAN SKELETAL REMAINS IN JARS FROM ARCHAEOLOGICAL SITE OF SAHAB, JORDAN: A BIO-ARCHAEOLOGICAL AND CONSERVATION STUDY
}

\author{
Abu Dalou ${ }^{1}$, A., Elserogy, A. ${ }^{* 2} \&$ Ibrahim, M. ${ }^{3}$ \\ ${ }^{1}$ Anthropology dept., Faculty of Archaeology \& Anthropology, Yarmouk Univ., Irbid, Jordan. \\ ${ }^{2}$ Conservation and Management of Cultural Resources dept., Faculty of Archaeology \& Anthropology, \\ Yarmouk Univ., Irbid, Jordan, Restoration dept., Faculty of Archaeology - Fayoum Univ. Fayoum, Egypt \\ ${ }^{3}$ Jordan Representative to the World Heritage Committee, Jordan.
}

E-mail: xserogy@yahoo.com

\begin{abstract}
This bio-archaeological and conservation study aimed to analyze and expand our understanding of the aspects of ancient people death practices, lived in Sahab, Jordan through conducting research on human skeletal remains found buried in Jars. After moving one of the big jars from the stores of Faculty of Archaeology and Anthropology - Yarmouk University of Jordan into the laboratory, the materials were separated and laid down in a scientific manner. Sex, age, and stature were estimated and pathologies were investigated. Samples were taken in order to monitor $\mathrm{pH}$, and to conduct FTIR, XRD, and XRF. The materials were cleaned used different types of standardized methods. After that, the skeletons were consolidated, and some broken parts were brought together. In the last stage, the skeletons were coated as a preventive measure. Analysis conducted on these human skeletal remains showed that three human skeletons (one adult female, and a fetus (unknown sex), and an infant (unknown sex) were buried together in this jar. The preservation was very good as predicted by the monitored value of bone and soil samples $\mathrm{pH}$ with an average of 7.4. Different scenarios of their death and burial practices will be discussed.
\end{abstract}

Keywords: Jordan, Sahab burial habits, Jars, Conservation, Bioarchaeology exchange.

\section{Introduction}

Archaeothanatology (Archaeology of death) is defined as the "the study of death and dying in antiquity and the circumstances surrounding them" [1]. This type of study is very important for bioarchaeologists and conservators to expand their understanding of the burial habits of past populations. One of the methods that enable them to do so is to study human skeletal remains unearthed from different archaeological sites of different archaeological periods. Burial habits vary in space and time. Analyzing these habits enable researchers to draw clearer pictures on some of the aspects of ancient culture and civilizations [2]. Furthermore, Chesson and Schaub [3] mentioned that many aspects of social complexity can be understood from bioarchaeological studies conducted on cemeteries. Understanding burial customs of past populations in Jordan attracted a number of archaeologists, bioarchaeologists, and conservators who aimed to study those habits from different points of view. Al-Shroman and Khawileh [4] published a thorough study in which they discussed burial practices through eras 
in Jordan from Natufians to Persians. In older study and mainly focus on burial habits in one single archaeological period, Ibrahim and Gordon [5] published a book in which both analyzed in details burial habits in Roman Period by studying

\section{The Archaeological Site}

Sahab is an important Archaeological site located in the southern part of Jordan, fig. (1-a). The site was excavated for several seasons under the supervision of Prof. Moawiyah Ibrahim. The most significant findings of these seasons of excavation were the findings of 1972 season. During that season, the team a cemetery at Queen Alia International Airport (QAIA). In this study, a multidisciplinary approach was performed on three human skeletal remains found in a big jar from archaeological site of Sahab, Southern Jordan.

unearthed eight burial jars in Tomb II Area C of Sahab Cave, which were dated back to Early Bronze Age (Ibrahim, Unpublished Report), fig. (1-b). Those jars were buried in a shape looked like "M". These materials were found in a good preservation condition with a significant amount of dirt on them.

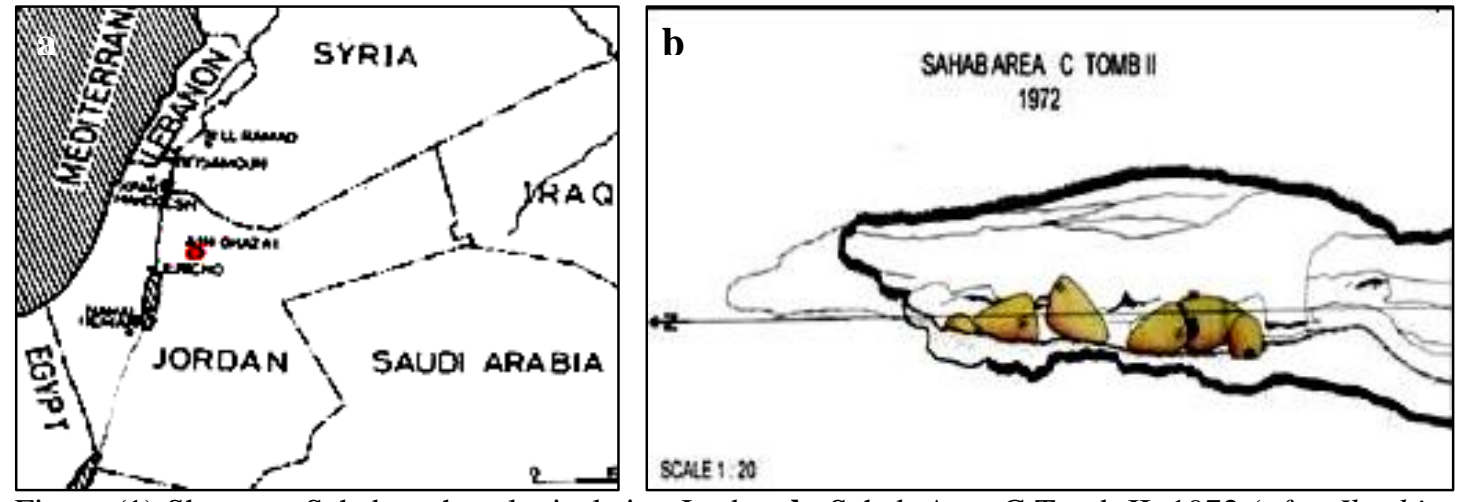

Figure (1) Shows ‥ Sahab archaeological site, Jordan, ㅁ. Sahab Area C Tomb II, 1972 (after Ibrahim, M., unpublished excavation report)

\section{Materials and Methods}

Three human skeletons were found in a burial jar stored in Faculty of Archaeology and Anthropology Storage, fig. (2-a,b). The jar was among eight, which were unearthed in 1972 excavation season

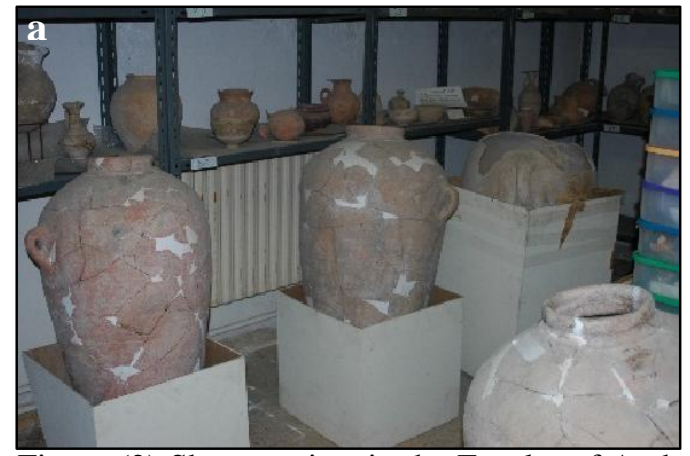

under supervision of Prof. Mouawiah Ibrahim. The jar was carefully transported from the store under the supervision of the two researchers to one of the laboratories in order to conduct this study.

Figure (2) Shows $\underline{\mathbf{a}}$. jars in the Faculty of Archaeology and Anthropology -Yarmouk Univ. Store, $\underline{\mathbf{b}}$. a jar with skeletal remains.

\subsection{Sexing the skeletons}

The sex of the first skeleton was determined based on some of the morp-

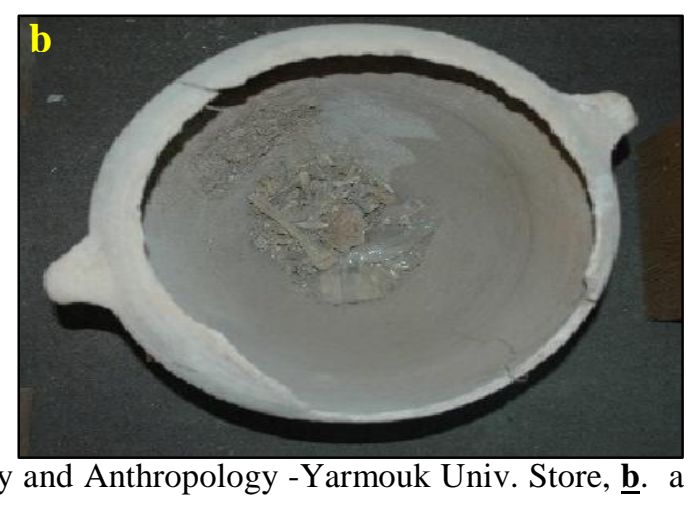

hological features of the hip bones, fig. (3-a,b,c). Both left and right hip bones were 
present. While the left one was broken into few fragments, the right into many fragments. The first sexual di-morphic feature to be examined was greater sciatic notch. Based on the rule of thumb, sex was determined as female, because greater sciatic notch was characterized as wide [6]. Furthermore, preauricular sulcus was very developed, based on which was conclude that this skeleton was for female [6]. The subpubic angle was wide on both left and right hip bone, which also indicated that this skeleton is of female [6]. Finally, the subpubic concavity was present on both hip bones [7], and this made us to reach the same determination. The sex of the two other skeletons was unknown, since the second one was fetus, and the third one was aged as (NB to 6 months old).
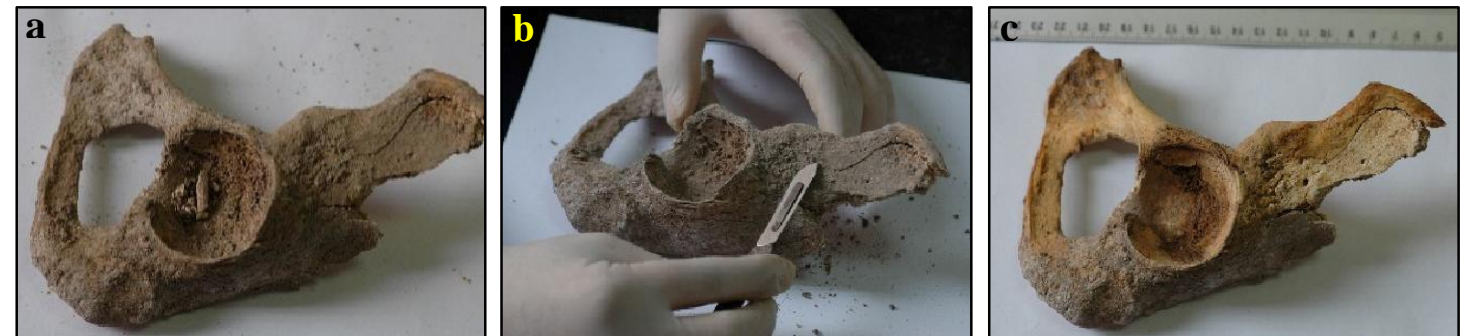

Figure (3) Shows $\underline{\mathbf{a}}$. the hipbone of the adult skeleton with a lot of dirty on it, $\underline{\mathbf{b}}$. the hipbone of the adult skeleton during mechanical cleaning, c. the hipbone of the adult skeleton during cleaning

\subsection{Ageing the Skeletons}

To age the first skeleton, several age determination procedures were employed. The first skeleton was aged based on the following methods: fusion of medial clavicle, fig. (4) and morphology of pubis symphysis and morphology of auricular surface [8]. The estimated age was 33 years. The other two skeletons were aged using different methods. The second skeleton was aged based on the maximum length of right and left ulna [9]. It was of fetus. The third skeleton was aged using the maximum length of left ulna, the age was (NB to 6 months). The stature of stature of the adult female skeleton was estimated only for adult female skeleton. It was determined based on the maximum length of right humerus after Trotter and Gleser [10] using the humerus equation as follows $\left[3.36^{*}\right.$ Humerus length +57.97 $\pm 4.45]$. The estimated stature was 140.30 $\mathrm{cm}$. However, this stature is considered as short compared to modern population but there is no other skeletal evidence to support the assumption of being dwarf.

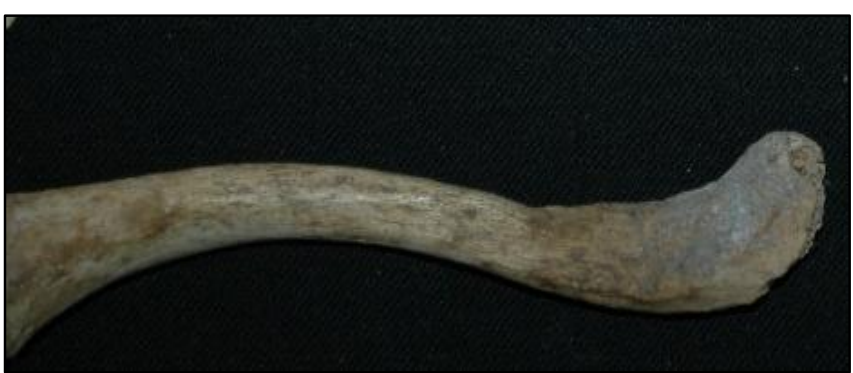

Figure (4) Shows the bone clavicle, which shows medial and distal epiphyseal union.

\subsection{Pathology}

The adult female skeleton was inspected visually for having any kind of disease. In spite of the development of a mild degree on the upper rim of one of the thoracic vertebra, and the presence of dental caries on the left lower second molar, it appeared that this skeleton is for individual who lived most of her life in a healthy manner. Osteophytes and dental caries will be discussed, in details, below. Osteophytes, a mild degree of osteophytes was observed on the upper and lower rims 
of three of the thoracic vertebra, fig. (5). Osteophyte or lipping can be defined as extra bone formed on the rim(s) of the vertebrae or on the margins of the joints. Osteophytes may be as a result of early stage of diffuse idiopathic skeletal hyperostosis (DISH) (Forestier's disease) [11]. In addition, a strong association exists between osteophytes and osteoarthritis
[12]. Furthermore, osteophyes may form as a result of imposed mechanical load on the back [13]. Some of that make us able to infer that this adult female involved in behavioral activities during she imposed mechanical stress on her vertebral column such carrying heavy objects.

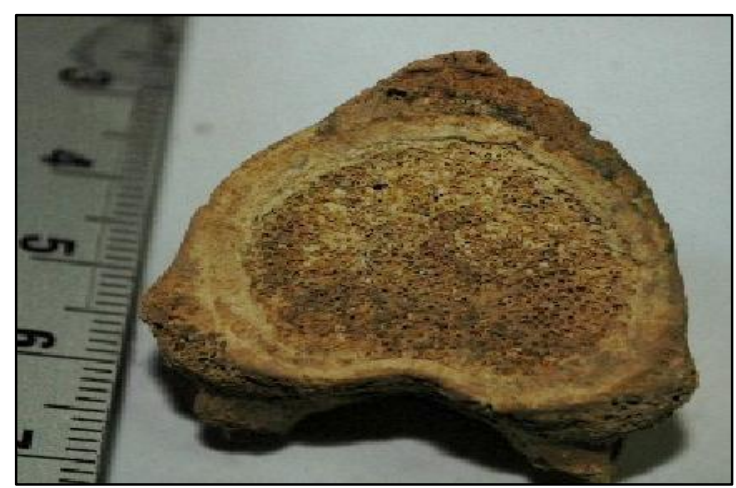

Figure (5) Shows mild degree of the osteophytes (Lipping) on the upper rim of one of the thoracic vertebra.

\subsection{Dental caries}

The adult female skeleton had displayed dental caries on the second lower molar, fig. (6). Rate of dental caries is a very informative indicator on the health of human teeth and can be used to reconstruct dietary habits among archaeological populations [14]. Newbrun [15] and Larsen [16] defined dental caries as demineralization of hard structures of teeth as a result of action of acidic materials from specific species of bacteria associated carbohydrates rich foods. A close link was established between the type of diet among archaeological populations and dental caries. To understand the patterns of change in prevalence and frequency of dental caries, several studies were conducted on different archaeological populations depended on different subsistence practices. In Limo recent published study [14]; the frequency, location, and severity of the dental caries of 5838 teeth from six Estonian archaeological populations dated back to Migration period (450 -600 AD) and Early Modern Times $\left(18^{\text {th }}\right.$ c.). Her study showed a gradual increase in frequency and degree of severity from Migration Period to early modern Period. In another study conducted on skeletal remains from Georgia Bight, Larsen et al., [17] showed a pattern of increase in the frequency of this type of dental disease few centuries pre-European contact as a result of intensification of maize agriculture.

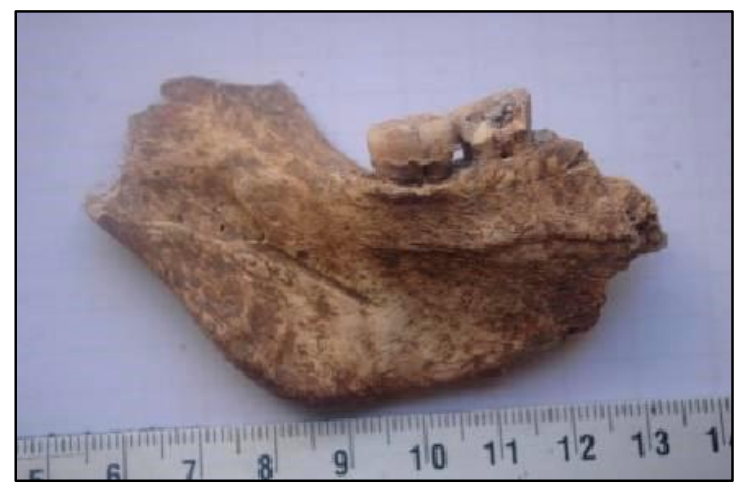

Figure (6) Shows dental caries on the second molar of the adult female skeleton 


\subsection{Investigation and analysis}

Since the preservation condition of the skeletons in the tomb was very good, it was necessary to monitor soil $\mathrm{pH}$ value. In order to do so, two soil samples were taken from the skeletons (One sample from the dirt attached to the adult skeleton and one from the soil attached to the jar) during procedure of cleaning. Two grams of each sample was immersed in a known volume of freshly prepared distilled water $(10 \mathrm{ml})$ for one hour, after that the $\mathrm{pH}$ electrode

\section{Results}

\subsection{Soil and bone $\mathrm{pH}$ test result}

$\mathrm{pH}$ value for bone and soil samples was (7.4), which represents the mean value of 3 readings for each sample (7.4-7.6). We conclude that the cause of bones presse-rvation for the long period of time in the burial environment is due

\subsection{XRD analytical result}

XRD investigation results proved that the samples findings indicated for the presence of Gypsum $\left(\mathrm{CaSO}_{4} .2 \mathrm{H}_{2} \mathrm{O}\right)$

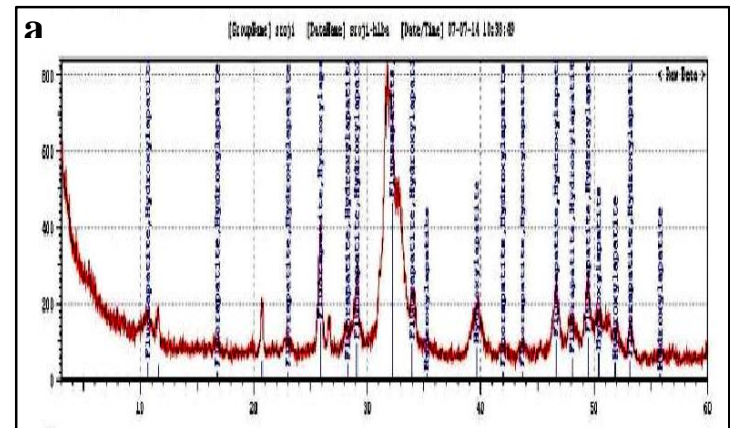

was immersed in the water, and then the $\mathrm{pH}$ value reported $(\mathrm{Ph}$ meter model 3151Germany). Within the same context, X-ray diffraction (XRD) analytical method was conducted on two samples; the first for one of the adult skeleton and the second for the soil. Fourier transform infrared spectroscopy (FTIR) was performed on the adult skeleton In addition, X-ray fluorescence (XRF) was conducted on a soil sample.

to its presence in a balanced suitable environment, where it is known as a protective for bones than the acidic ones, which cause significant deterioration for the bones [18].

and Quartz (Sio2), which led us to conclude that the soil was humid, fig. (7$\mathrm{a}, \mathrm{b})$.

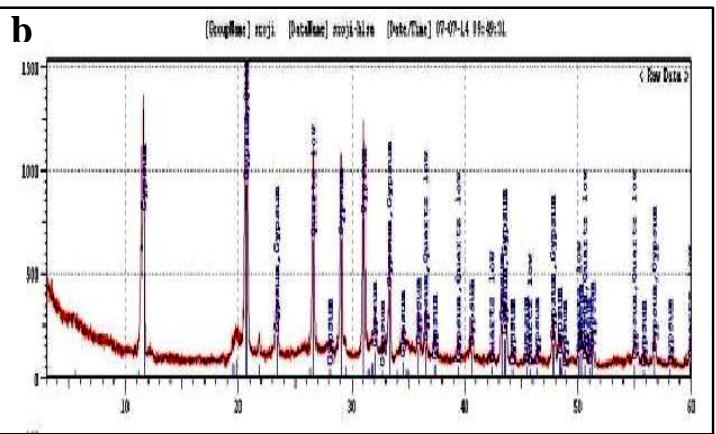

Figure (7) Shows XRD patterns of $\mathbf{a}$. bone, $\underline{\mathbf{b}}$. soil investigated samples

\subsection{FTIR analytical result}

The results of FTIR showed the presence of the peak of absorption at $\left(565 \mathrm{~cm}^{-1}, 605 \mathrm{~cm}^{-1}\right.$, and $\left.595 \mathrm{~cm}^{-1}\right)$ indicated that hydroxyapatite did not change. In addition, the skeletons were in a good condition. The peak of absorption at $872 \mathrm{~cm}^{-1}$ indicated for the presence of Calcite $\left(\mathrm{CaCo}_{3}\right)$ in the bone, fig. (8).

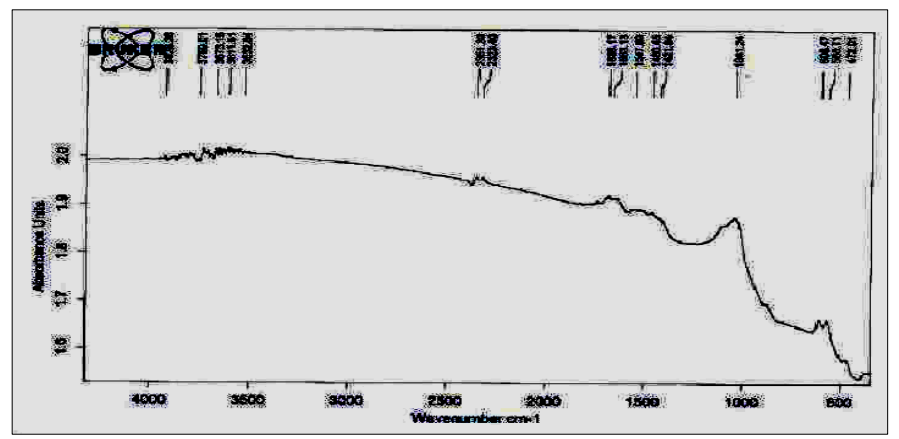

Figure (9) Shows FTIR patterns of bone investigated samples 


\section{XRF analytical result}

The investigated results of XRF proved that the soil sample composed essentially of $\mathrm{Ca}, \mathrm{Si}, \mathrm{Fe}$ and $\mathrm{S}(90.7 \%)$ with

Table (1) XRF analytical results of investigated soil sample

\begin{tabular}{lll}
\hline No. & Elements & Concentrations \% \\
\hline $\mathbf{1}$ & $\mathrm{Si}$ & 16 \\
$\mathbf{2}$ & $\mathrm{S}$ & 15 \\
$\mathbf{3}$ & $\mathrm{K}$ & 3.8 \\
$\mathbf{4}$ & $\mathrm{Ca}$ & 44.1 \\
$\mathbf{5}$ & $\mathrm{Sc}$ & 0.5 \\
$\mathbf{6}$ & $\mathrm{Ti}$ & 1.3 \\
$\mathbf{7}$ & $\mathrm{Mn}$ & 0.26 \\
$\mathbf{8}$ & $\mathrm{Fe}$ & 15.6 \\
\hline $\mathbf{9}$ & $\mathrm{Pd}$ & 3 \\
\hline
\end{tabular}

\section{Treatment and Conservation}

\subsection{Cleaning process}

Because of the presence of hard dirt on the skeletons and in order to examine many of their parts for sexing and aging and diagnosing diseases, this procedure was inevitable. We started the mechanical cleaning for bone with light brushes and dental tools. But for very hard dirt, we used chemical methods by using water and alcohol or acetones (the use of alcohol and acetone will facilitate object drying). In order to remove the rest of hard dirt, a combination of both mechanical and some other elements wit percentage (9.3 $\%$ ), as listed in tab. (1) and fig. (9).

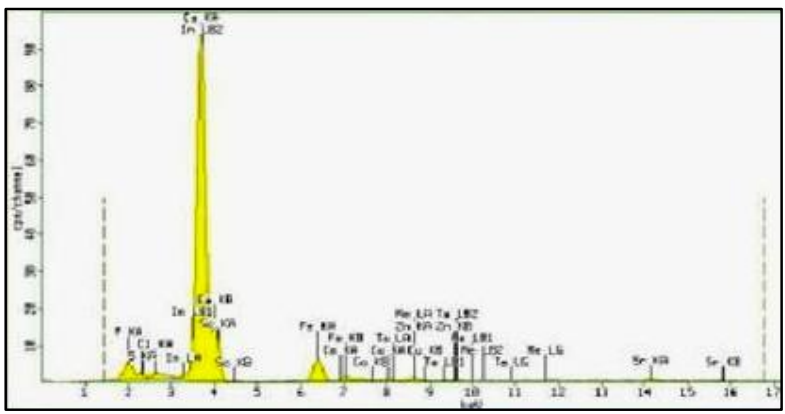

Figure (9) Shows XRF patterns of investigated soil sample
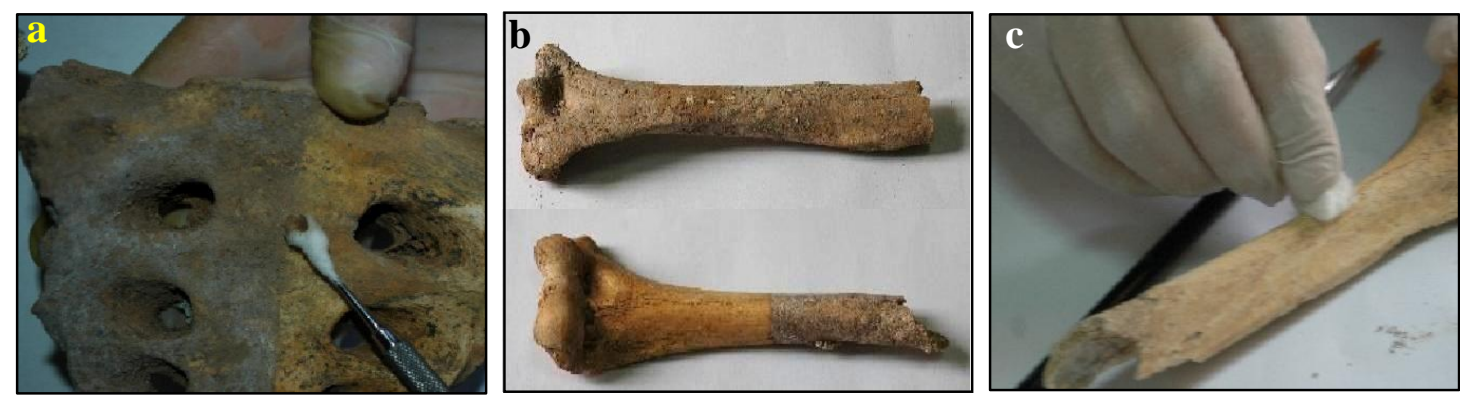

Figure (10) Shows a. wet cleaning on part of the sacrum, $\mathbf{b}$. Humeri of adult skeleton before and during mechanical cleaning, $\underline{\mathbf{c}}$. Humerus of adult skeleton after cleaning

\subsection{Gluing the broken parts}

After experimental study on bone samples to choose the best concentration of the adhesive that will be used, and after looking at previous experimental studies by specialized conservators in the field of bone conservation, a thick viscous mixture of Paraloid B-72 dissolved in

acetone ( $20 \%$ concentration) was used to glue the broken parts. A small fragment of the lower right side of the adult female sacrum was glued with the bigger part. Another glued parts were fragments of the ileum of left hip bone [20,21], fig. (11-a,b). 

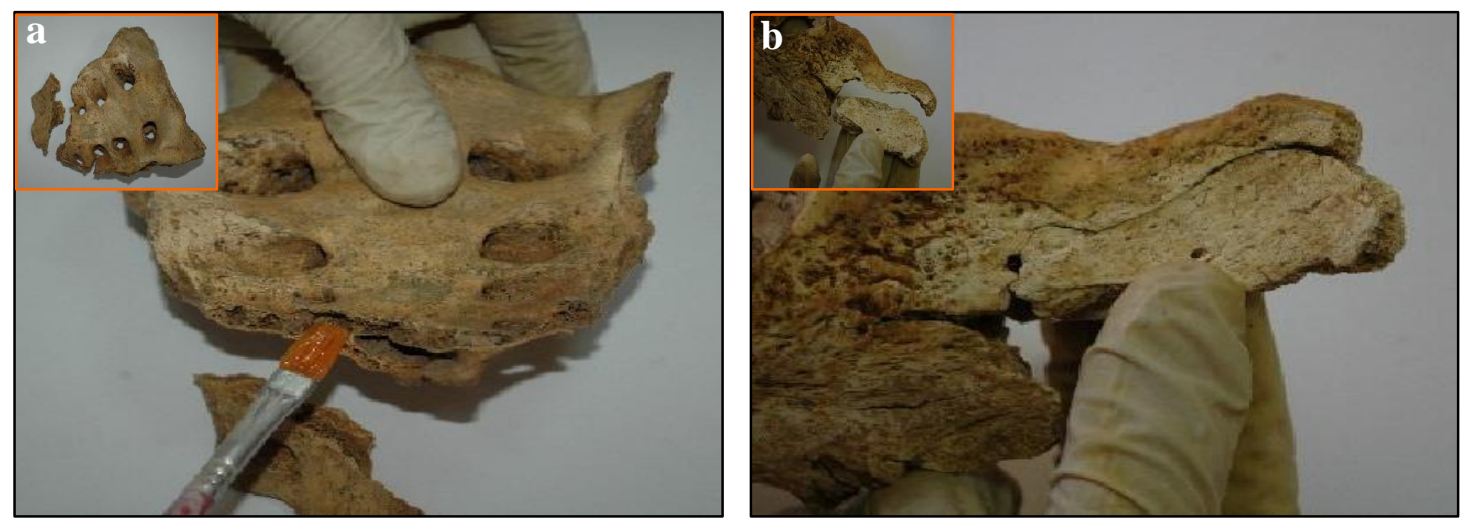

Figure (11) Shows $\underline{\mathbf{a}}$. sacrum of the adult skeleton after gluing with small image in its broke state, $\underline{\mathbf{b}}$. gluing the fragments of the ileum with small image in its broke state

\subsection{Consolidation and coating of the bones}

After bones cleaning, we slowly drying them by organic solvents (acetone), then a $3 \%$ solution of paraloid B-72 was used for bone consolidation [22]. Then a light layer of resin was applied by brush. After its layer dried, a second layer of resin $(5 \%$ Solution of paraloid B-72) was applied to get sufficient absorption of the resin by the object to accomplish consolidation [23], fig. (12$a, b, c)$.
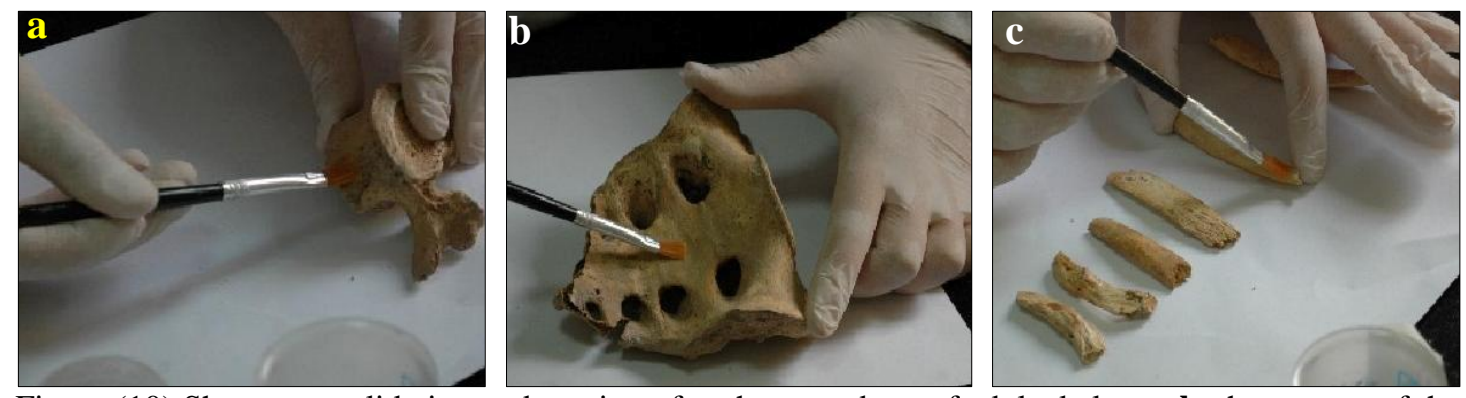

Figure (10) Shows consolidation and coating of $\underline{\mathbf{a}}$. the verterbrae of adult skeleton, $\underline{\mathbf{b}}$. the sacrum of the adult, $\underline{\mathbf{c}}$. some of the bone fragments of the adult skeleton

\section{Discussion}

These three skeletons were unearthed buried in a big jar and dated back to Early Iron Age. Different scenarios will be discussed on the way they were buried and the rituals associated with their death. The first possibly practiced burial habit type was a primary type, in which the three individuals of the same nuclear family buried in the jar. An evidence that might indicate to that, that the opening of the jar was broken to allow them to put the bodies of their dead people inside it. The second possible scenario that this type of burial habits is a secondary type, since that the population lived in Sahab

\section{Recommendations}

Another ongoing study is on the skeletons found in a second Jar unearthed at that period of time buried their dead in the ground, and after the flesh decomposed, they brought the skeletal remains and reburied them in the big Jars. It might be that the three skeletons were for individuals belonged to one nuclear family, a mother with her fetus and infant. The mother probably died while she was pregnant (second trimester). As predicted by value of $\mathrm{pH}$, the preservation was very good. As a result of that, the condition of the skeletal remains was very good. Furthermore, several methods of cleaning were performed in order to remove the dirt and other materials from the skeletons.

from the same archaeological site. Dating using Carbon-14 and genetic study will be 
conducted in order to find out the relation between those individuals. We must work as one team (teamwork) in conservation field of archaeological bone (anthropology, archeology, and conservator). The best conservation materials for bone consolidation, coating them with Paraloid B72, this because paraloid B-72 is very durable, nonyellowing and has excellent resistance to water, alcohol, alkalis and acid. In addition, it has an excellent flexibility, and it is more resistant to discoloration even at high temperatures. Providing suit-able environment condition in the museums to avoid any farther damage and biodeterioration for archeological objects, through; monitoring and controlling the relative humidity and temperature.

\section{Conclusion}

The findings of this research paper enable us to reach the following conclusion; dead individuals of the same nuclear family were buried together in primary or secondary burial tomb or jar.

\section{Acknowledgments}

First of all, we would like to thank Professor Abudulla Al Shorman for his assistance. We would like to thank Hadeel Nawasreh, an undergraduate conservation and cultural resources management student for her efforts in the laboratory. In addition, we send our great thanks to Mr. Mahmoud Abu Dalou, a store staff member. We thanks also Sana' Khasawneh, a staff member of the laboratory unit of the faculty of archaeology and anthropology.

\section{References}

[1] Al-Shorman, A., (2007). The arcaheothanatology of Jordan, Lectures in Archaeothanatology, Deanship of Research and Graduate Studies, Yarmouk Univ., Irbid, Jordan.

[2] Brunson-Hadley, J. \& Mitchell, D., (2001). Ancient burial practices in the American Southwest: Archaeology, Physical Anthropology, and Native American Perspectives, Albuquerque: Univ. of New Mexico Press, USA.

[3] Chesson, M. \& Schaub R., (2007). Death and dying on the Dead Sea Plain, Fifa, Khirbat al-Khanazir, and Bab adh-Dhra' cemeteries, in Levy, T., MichèlDaviau, P., Younker, R. \& Shaer, M. (eds.) Crossing Jordan: North American contributions to the archaeology of Jordan. London, pp. 253-260.

[4] Al-Shorman, A. \& Khwaileh, A., (2011). Burial practices in Jordan from the Natufians to the Persians, Estonian J. of Archaeology, Vol. 15, pp: 88-108.

[5] Ibrahim, M. \& Gordon, R., (1987). Cemetery at Queen Alia interna- tional airport. Vol.1 Harrassowitz, O., Wiesbaden.

[6] Bass, W., (1995). Human osteology: A laboratory and field manual. $4^{\text {th }}$. ed., Missouri Archaeological Society, Columbia.

[7] White, T., (2000). Human osteology. $2^{\text {nd }}$, Academic Press, San Diego.

[8] Lovejoy, C., Meindl, R., Pryzbeck, T. \& Mensforth, R., (1985). Chronological metamorphosis of the auricular surface of the ilium: A new method for the determination of adult skeletal age at death, American J. of Physical Anthropology, Vol. 68, pp: 15-28.

[9] Jonnston, F. (1962). Growth of the long bones of infants and young children at Indian knoll. Human Biology, Vol. 23, pp: 66-81.

[10] Trotter, M. \& Gleser, G., (1952). Estimation of stature from long bones of the American whites and Negroes, American J. of Physical Anthropology, Vol. 10, pp: 463-514. 
[11] Rogers, J., Shepstone, L. \& Dieppe, P. (1997). Bone formers: osteophyte and enthesophyte are positively associated, Annals of the Rheumatic Diseases, Vol. 56 (2), pp:85-90

[12] Moskowitz, R. \& Goldberg, V., (1987). Studies on osteophytes pathogenesis in experimentally induced osteoarthritis, The Journal of Rheumatology, Vol. 14, pp: 311-320.

[13] Kim, D., Kim, M., Kim, Y. Oh, C. \& Shin, D., (2012). Vertebral osteophytes of pre-modern Korean skeletons from Joseon tombs, Anatomy and Cell Biology, Vol. 45 (4), pp: 274-281.

[14] Limbo, J., (2013). The frequency and pattern of dental caries in archaeological populations in Estonia, Papers on Anthropology, Vol. 22, pp: 121-132.

[15] Newbrun, E., (1982). Sugar and dental caries: a review of human studies, Science, Vol. 217, pp: 418-423.

[16] Larsen, C., (1982). The anthropology of St. Catherines Island: 3 prehistoric human biological adaptation, Anthropol. Pap. Am. Mus. Nat. Hist., Vol. 57 (3), pp: 255-270.

[17] Larsen, C., Shavit, R. \& Griffin, M., (1991). Dental caries evidence of dietary change: an archaeological context, Advances in dental anthropology, pp: 179-202.

[18] Abdel-Maksoud, G. \& AbdelHady, M., (2011). Effect of burial environment on crocodile bones from Hawara excavation, Fayoum,
Egypt: J. of Cultural Heritage, Vol. 12 (2), pp: 180-189.

[19] Plenderleith, H., (1979). The conservation of antiquities and works of art, Oxford Univ. Press, London.

[20] Podany, J., Garland, K., Freeman, W., \& Rogers, J. (2001) Paraloid B72 as a structural adhesive and as a bar-rier within structural adhesive bonds: Evaluations of strength and reversibility. J. of the American Institute for Conservation, Vol. 40 (1), pp: 15-33

[21] Koob, S., (1986). The use of Paraloid B-72 as an adhesive: Its application for archaeological ceramics and other materials, Studies in Conservation, Vol. 31, pp: 7-14.

[22] El Sorogy, A. AL Ybroodi, R. \& Kafafi, Z., (2015). Conservation of an archaeological human plastered skull displayed in the Jordanian heritage museum-Yarmouk Univ. A case study, Adumatu Journal, Vol. 32, pp: 21-30

[23] Abu Dalou, A., El Sorogy, A., AlShorman, A., Al rousan, M. \& Khwaileh, A., (2017). Bioarchaeology, conservation, and display of a $16 \mathrm{k}-$ human skeleton, Jordan. Mediterranean Archaeology and Archaeometry, Vol. 17 (1), pp: 251-263 